\title{
THE EFFECT OF TOTAL PRESSURE ON VAPORIZATION OF ALKALIS FROM PARTIALLY MOLTEN CHONDRITIC MATERIAL
}

\author{
Taro SHIMAOKA ${ }^{1}$ and Noboru NAKAMURA ${ }^{1,2}$ \\ ${ }^{1}$ Department of Science of Material Differentiation, Graduate School of Science and \\ Technology, Kobe University, ${ }^{2}$ Department of Earth Sciences, Faculty of Science, Kobe \\ University, Nada, Kobe 657, Japan
}

\begin{abstract}
In order to examine the effect of total pressure on vaporization of alkalis ( $\mathrm{Na}, \mathrm{K}, \mathrm{Rb}$ ) from a partially molten chondritic material, heating experiments were carried out under various He gas pressures $\left(\sim 10^{-5} \sim 10^{-1}\right.$ torr $)$ at $1300^{\circ} \mathrm{C}$. The rate of vaporization decreased in the order of $\mathrm{Na}>\mathrm{K}>\mathrm{Rb}$ with the increasing of the pressure, and reached a minimum at $\sim 10^{-1}$ torr.
\end{abstract}

\section{Introduction}

Alkali metals are moderately volatile at high temperatures and their vaporization behavior can constrain melting conditions of lunar and meteoritic materials (Gibson and Hubbard, 1972; Kreutzberger et al., 1985; Tsuchiyama et al., 1981; Matsuda et al., 1990).

We have conducted a series of vaporization experiments to study vaporization behavior of alkalis from a partially molten chondritic material (Shimaoka and Nakamura, 1989). Our results suggest that the vaporization is controlled mainly by the loss of elements from the partial melt, which is similar to the case of total melt (Tsuchiyama et al., 1981). However, there exists a systematic difference in vaporization rates between the two results. The vaporization rate can be influenced by total pressure, oxygen fugacity, and the chemical composition of charge as well as temperature. In this work, a heating experiment of a chondritic material was carried out under various total pressures $\left(\sim 10^{-5}-\sim 10^{-1}\right.$ tor $\left.r\right)$ at a constant temperature $\left(1300^{\circ} \mathrm{C}\right)$ to investigate the effect of total pressure on vaporization of alkalis.

\section{Experimental}

The apparatus and the general procedure used for the vaporization experiment were described previously (Shimaoka and Nakamura, 1989). In this work, the starting material with fine grain-size ( $\phi<10$ um), similar to sample A in our previous work, was newly prepared from the Etter (L5) chondrite. Total pressure $\left(\sim 10^{-5}-\sim 10^{-1}\right.$ torr $)$ was adjusted using helium 79

A.C. Levasseur-Regourd and H. Hasegawa (eds.), Origin and Evolution of Interplanetary Dust, 79-82. (Q) 1991 Kluwer Academic Publishers, Printed in Japan. 
gas with high purity (99.999\%). The sample was heated at a constant rate $\left(\sim 30^{\circ} \mathrm{C} / \mathrm{min}\right)$ up to $1300^{\circ} \mathrm{C}$. After maintaining this temperature for $40 \mathrm{~min}$, the power supply of the furnace was cut off and then the sample was quenched with a cooling rate of $\sim 600^{\circ} \mathrm{C} / \mathrm{min}$. A run product was broken into fragments and divided into two parts. One part was used for preparation of thin section. The other part was crushed to fine powder and subjected to analyses of $\mathrm{Na}$ by atomic absorption spectroscopy, and of $\mathrm{K}$ and $\mathrm{Rb}$ by isotope dilution mass spectrometry. The proportions of holes and melt in the run products were estimated from the SEM backscattered electron images (Figure 1) of run products (Shimaoka and Nakamura, 1989).

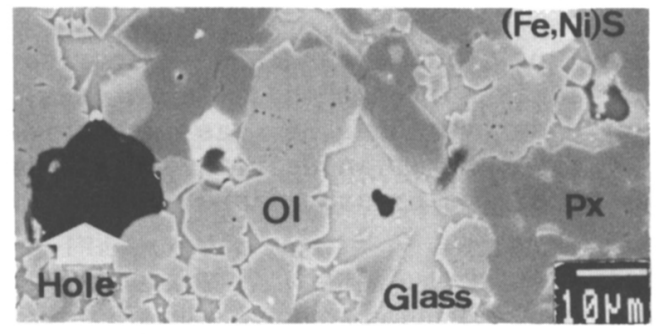

Figure 1. Back-scattered electron image of one of run products $\left(1300^{\circ} \mathrm{C}, 40 \mathrm{~min}\right)$. 01 : olivine, $\mathrm{Px}$ : pyroxene, ( $\mathrm{Fe}, \mathrm{Ni}) \mathrm{s}$ : pentrandite

\section{Result and Discussion}

\subsection{PREVIOUS STUDY}

Previously, we obtained the following equation applicable to the vaporization of $\mathrm{Na}$ from a partial melt (Shimaoka and Nakamura, 1989):

$$
\ln \left(\mathrm{C} / \mathrm{C}_{0}\right)=-\mathrm{k}\left(\mathrm{f} \cdot \mathrm{s}_{\text {tot }} / \mathrm{v}_{\mathrm{p}}\right) \mathrm{t}
$$

where $\mathrm{C}$ and $\mathrm{C}_{0}$ are the concentrations in run product and starting material respectively, $k, s_{\text {tot }}$ and $v_{p}$ are the vaporization rate, the overall surface area and the volume of partial melt of charge respectively, $t$ is the heating duration and $f$ is the overall proportion of effective surface area of melt to total surface area of charge. The $f$ value is tentatively estimated to be 0.2 . Assuming that $f, s_{\text {tot }}$ and $v_{p}$ are constant during the heating, a linear correlation between $t$ and $\ln \left(\mathrm{C} / \mathrm{C}_{0}\right)$ is expected. In Figure 2, results of an additional heating experiment for Na of this work are compared with those of previous work. In this diagram, all data points distribute along a linear curve, indicating a good reproducibility of vaporization rate in our heating experiments. As previously mentioned, the vaporization rate $(k)$ calculated from the slope of regression lines are systematically high compared to those of the same temperature range obtained by extrapolating Tsuchiyama et al. (1981)'s values. 


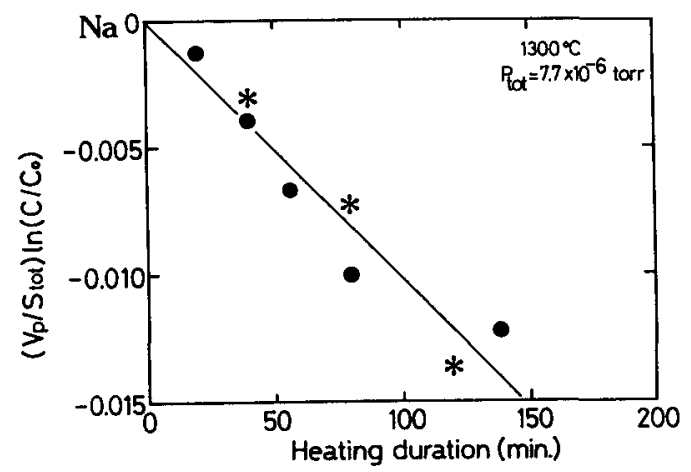

Figure 2. Plot of relative concentration of $\mathrm{Na}$ in heated samples corrected for effects of holes and partial melts as a function of heating duration. Symbols of stars and circles represent the present and previous results, respectively (Shimaoka and Nakamura, 1989).

\subsection{EFFECT OF TOTAL PRESSURE}

Applying equation (1), the vaporization rates of alkalis at various total pressures are obtained (Table 1 and Figure 3 ): in general, the vaporization rates of alkalis decrease with increasing total pressures. It is noted that the rate of vaporization decreases gradually for $\mathrm{Na}$ but abruptly for $K$ and $R b$ at $\sim 10^{-1}$ torr. Actually, almost no vaporization loss of $\mathrm{Rb}$ was detected for the run product at $\sim 10^{-1}$ torr. It is interesting to note, that the pressure effect is greatest for $\mathrm{Rb}$ and smallest for $\mathrm{Na}$.

TABLE 1. Results for run products at $1300^{\circ} \mathrm{C}$

\begin{tabular}{|c|c|c|c|c|c|}
\hline Run No. & $89 \mathrm{~A}$ & $88 \mathrm{~A}$ & $86 \mathrm{~A}$ & $87 \mathrm{~A}$ & $90 \mathrm{~A}$ \\
\hline Duration (min) & 40 & 40 & 40 & 40 & 40 \\
\hline Total pressure (torr) & $7.7 \times 10^{-2}$ & $7.7 \times 10^{-3}$ & $7.7 \times 10^{-4}$ & $7.7 \times 10^{-5}$ & $7.7 \times 10^{-6}$ \\
\hline Holes $(\%) * 1$ & 10.4 & 9.2 & 11.0 & 8.3 & 9.5 \\
\hline Deg. of melt $(\%) * 1$ & 41.9 & 48.9 & 43.6 & 55.9 & 39.2 \\
\hline Olivine $\mathrm{Fa}$ (mol\%) & 27.5 & 26.9 & 25.1 & 25.0 & 26.3 \\
\hline $\mathrm{Na}(\mathrm{ppm})$ & 2074 & 790 & 239 & 384 & 548 \\
\hline $\mathrm{K}(\mathrm{ppm})$ & 454 & 315 & 235 & 238 & 286 \\
\hline $\mathrm{Rb}(\mathrm{ppm})$ & 1.32 & 0.962 & 0.836 & 0.822 & 0.979 \\
\hline $\mathrm{k}_{\mathrm{Na}}\left(\mathrm{cm}^{3} / \mathrm{min} \cdot \mathrm{cm}^{2}\right) * 2$ & $1.07 \times 10^{-4}$ & $1.89 \times 10^{-4}$ & $2.43 \times 10^{-4}$ & $2.93 \times 10^{-4}$ & $2.81 \times 10^{-4}$ \\
\hline $\mathrm{k}_{\mathrm{K}}\left(\mathrm{cm}^{3} / \mathrm{min}^{\cdot} \mathrm{cm}^{2}\right) * 2$ & $9.83 \times 10^{-6}$ & $4.18 \times 10^{-5}$ & $5.59 \times 10^{-5}$ & $7.69 \times 10^{-5}$ & $6.39 \times 10^{-5}$ \\
\hline $\mathrm{k}_{\mathrm{Rb}}^{\mathrm{n}}\left(\mathrm{cm}^{3} / \mathrm{min} \cdot \mathrm{cm}^{2}\right) * 2$ & 0 & $2.79 \times 10^{-5}$ & $3.33 \times 10^{-5}$ & $4.84 \times 10^{-5}$ & $3.34 \times 10^{-5}$ \\
\hline
\end{tabular}

*1 See Shimaoka and Nakamura (1989).

*2 Vaporization rates of alkali metals ( $\mathrm{Na}, \mathrm{K}, \mathrm{Rb}$ ) calculated using eq. (1) with $f=1$ (see text).

Concentration of alkalis in the starting material;

$\mathrm{Na}=6550 \mathrm{ppm}, \mathrm{K}=506 \mathrm{ppm}, \mathrm{Rb}=1.32 \mathrm{ppm}$ 


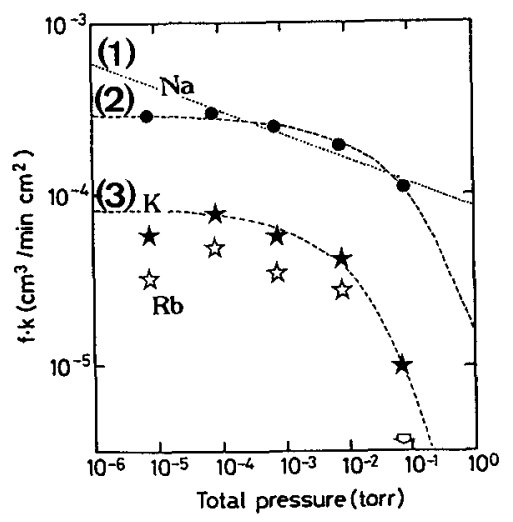

Figure 3. Plot of the vaporization rate of alkali metals as a function of total pressure. The regression lines are:

(1) $\log (f \cdot k)=-0.142 \log P_{\text {tot }}-4.08$

(2) $\log (\mathrm{f} \cdot \mathrm{k})=-1.34 \exp \left(\log \mathrm{P}_{\text {tot }}\right)-3.54$

(3) $\log (f \cdot k)=-2.79 \exp \left(\log P_{\text {tot }}\right)-4.08$

Inspection of the least square fits indicates that an exponential curve ((2) and (3) in Figure 3 ) is best fitted to the data points. However, the physical meaning of exponential function is not clear. For simplification, we tested a linear curve ((1) in Figure 3 ) to compare with the data obtained by Tsuchiyama et al.(1981). The vaporization rate of $\mathrm{Na}$ was calculated to be $1.6 \times 10^{-4} \mathrm{~cm}^{3} / \mathrm{min} \cdot \mathrm{cm}^{2}$ at $1300^{\circ} \mathrm{C} \quad(\mathrm{f}=0.2)$ by extrapolating this 1 ine to $1 \mathrm{~atm}$. This value seems to be consistent with the value $\left(0.5-1.7 \times 10^{-4} \mathrm{~cm}^{3} / \mathrm{min} \cdot \mathrm{cm}^{2}\right)$ calculated from Tsuchiyama's experiment at the same temperature and oxygen partial pressure $\left(10^{-11.6}\right.$ atm). Since data points (particularly at high pressure) are still limited, more work may be needed to confirm the present result.

We thank Mrs T. Baba and N. Miyano for the setting up the programmable controller, and Dr. K. Yamamoto for the support of this work.

\section{REFERENCES}

Gibson, E. K., Jr. and Hubbard, N. J. (1972) 'Thermal volatilization studies on lunar samples', Proc. Lunar Conf. 3rd, 2003-2014.

Kreutzberger, M. E., Drake, J. V. and Lewis, V. A. (1985) 'Origin of the Earth's Moon: Constrains from alkali volatile trace elements', Geochim. Cosmochim. Acta 49, 91-98

Matsuda, H., Nakamura, N. and Noda, S. (1990) 'Alkali(Rb/K) abundances in Allende chondrules: Implication for the melting conditions of chondrules', Meteoritics 25, 137-143.

Shimaoka, T. and Nakamura, N. (1989) 'Vaporization of sodium from a partially molten chondritic material', Proc. NIPR Symp. Antarct. Meteorites 2, 252-267.

Tsuchiyama, A., Nagahara, H. and Kushiro, I. (1981) 'Volatilization of sodium from silicate melt spheres and its application to the formation of chondrules', Geochim. Cosmochim. Acta 45, 1357-1367. 